but is often useful as an illustration, and, without pressing the resemblance too far, the organisation of the Himalayan mountains may be compared to that of a great army, composed of many thousands of individual soldiers, grouped in reginents, these, again, in brigades and divisions, each having a separate individuality; but the individuality of the soldier differs from that of the regiment to which he belongs; this, again, merges in the individuality of the brigade, and the whole in that of the army. So with mountains, the peaks may be grouped into massifs, these into ranges, a series of which may form a great chain or system like that of the Himalayas or the Andes; but just as the brigades of an army are not each extended along the whole front, so the ranges do not extend along the whole length of the system. Each in turn comes to an end, and the chain is taken up by another, not as a direct continuation, but overlapping the end, so that the direction of the individual ranges is oblique to that of the system as a whole. Any other arrangement would probably be as physically impossible, with material such as that of which the earth's crust is composed, as the mar- of lofty, snow-clad peaks, misleading if meant as a name of a mountain range or system. Range it is not, for Dr. Hedin is clear enough on this point, as he repeatedly speaks of the separate ranges of which it is composed, and gives their number as no less than ten; mountain system it equally is not, having no separate existence. If a new name is required at all, it must be one which will unite these ranges with the Himalayas, not one which suggests a separation, for the valleys of the Sanpo and Indus no more separate the mountains on either side of them than, on a smaller scale, are the analogous valleys of the Rhone and the Rhine a reason for splitting up the unity of the Alps.

This criticism must not be taken as in any way a disparagement of Dr. Hedin's achievements; there can be but one opinion of the brilliance of his exploration and of the courage and determination with which he overcame the obstacles in his way. The publication of a detailed account of his travels will necessarily form an important addition to our knowledge of central Asia, but the fullest recognition of its importance does not involve an acceptance of Dr.

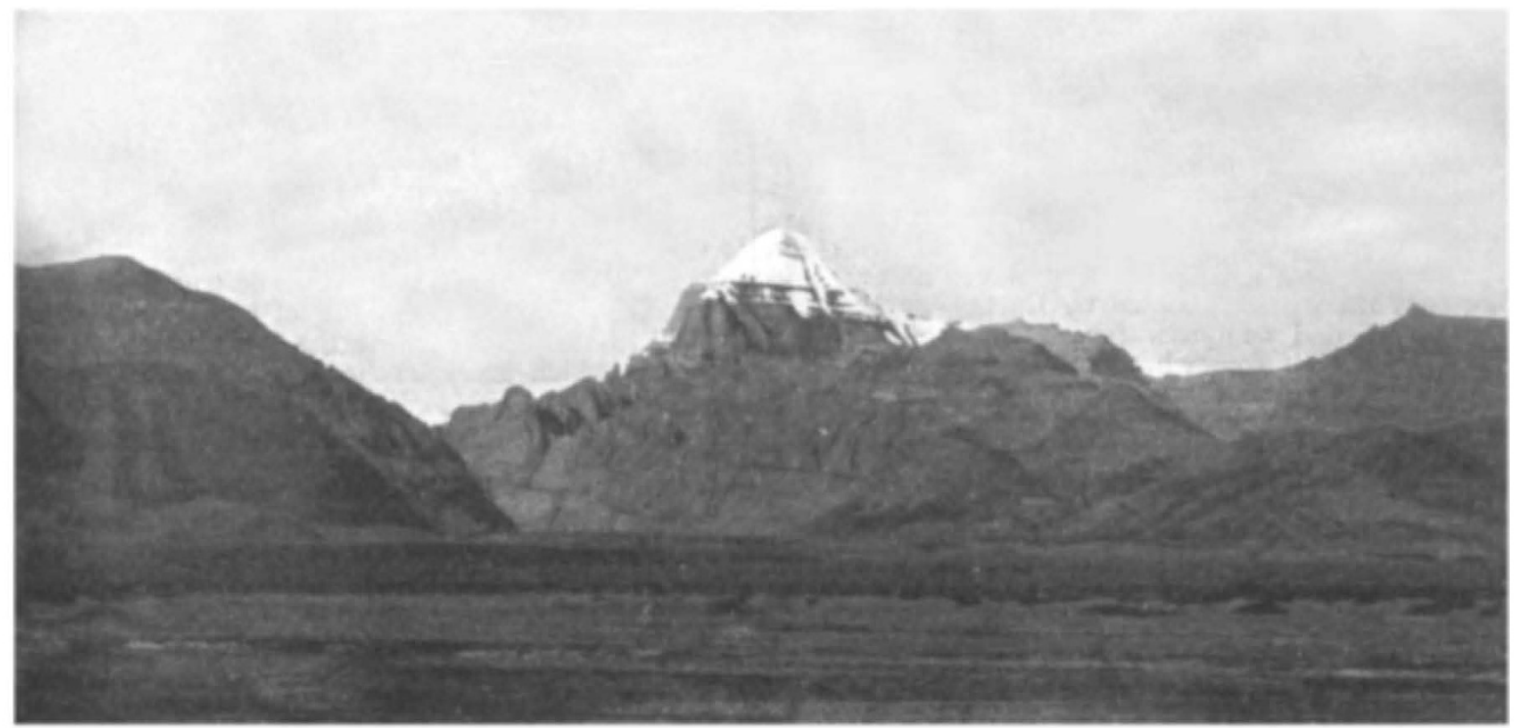

Kailas from the south-west From the Geographical Journal.

shalling of an army in brigades or divisions drawn up in lines extending along the whole length of the front would be militarily impracticable.

This interpretation of the orography of the Himalayas is borne out by such maps as we possess, and especially by those maps attached to Messrs. Burrard and Hayden's valuable sketch of the Himalayas, which exhibit the facts, rather than Colonel Burrard's interpretation. In these it will be seen that the high peaks of the Himalayas do not form a single range, but rather a band crossed obliquely by a series of ranges, and if we are to group these individual ranges into a single system, and to include in it the lesser ranges lying to the north and south, there is no reason, geographical or geological, for separating it from the mountains of southern Tibet and the northern territories of Cashmere. Structurally and orographically, the whole of the mountains between the Indian plains and the lake region of central Tibet belong to one great system, and the term which Dr. Hedin wishes to introduce is either unnecessary or misleading; needless if it merely indicates the country north of the first belt No. 2065 , VOL. 80]
Hedin's deductions, nor does a difference of opinion in regard to them imply any question of the accuracy of his observations.

\section{THE TEACHING OF GEOMETRY.}

$T \mathrm{HE}$ circular recently issued by the Board of Education on "The Teaching of Geometry and Graphic Algebra"' is an important document from at least two points of view. First, it has a very considerable educational value in indicating the successive steps or stages which it is proper for a teacher to take, and, secondly, it supplies information as to tine way in which the changes, introduced mainly by the Mathematical Association, have worked out. Those who have advocated the reformation of the teaching of geometry will be glad to know that the verdict of the Board of Education is favourable. "It should be stated at the outset that the general effect has been beneficial."

The reformers had most serious difficulties to face, the greatest, perhaps, being the almost divine authority 
attributed in England to Euclid's definitions, postulates, axioms, and propositions. Euclid's system was here regarded as the highest, and an infallible, type of logical accuracy. That it is still so regarded by some people is evident from the somewhat flippant and jesting comments made on the circular of the Board of Education in some of the daily papers. It may not be hopeless to point out to the writers of such comments that Euclid in at least one instance contradicts himself. His definition of a circle, for example, makes it to be, not a curve, but a surface : " a circle is a plane figure bounded by one line which is called the circumference." This clearly makes a circle to be a surface, and, moreover, it is lacking in definiteness, because it does not say whether the planebounded figure is that which is contained within the circumference, or that infinite external space which lies outside. Again, if a circle is a plane surface, what becomes of the proposition that two circles can intersect in only two points? Further, Euclid made the mistake of supposing that every geometrical concept can be defined, whereas there are some that can be only described: witness his attempted definition of a straight line, which merely encourages a pupil to deceive himself with a vague word.

The imperfections of Euclid are an old controversy which need not be enlarged upon. His merit as a logician is very great, and his logic is, on the whole, a type of accurate reasoning. Those who took part in reforming his system sought at once to preserve his logical excellence and to improve the subjectmatter on which it was to be exercised. This they tried to do by familiarising the beginner with the main concepts of geometry in ways more natural and more easy than those adopted by Euclid-by an early use of rule and compass, for example, which dispansed with that somewhat complicated and ridiculous problem which forms the very second proposition of Book i., "through a given point to draw a right line equal to a given finite right line," a most gratuitous stumbling-block to the beginner. They assumed the potent Baconian principle that "examples give a quicker impression than arguments." There is no doubt that the new system has made geometry much more easy in its initial stages for the young pupil, but it contains one great element of langer-it may, to a great extent, replace strict logic by rule of thumb, and accurate expression by slipshod language. Those who have to examine papers on geometry sent by pupils from scores of different schools must admit that this danger has not been averted, and the reason is easily found. We are at present teaching geometry on syllabuses. So long as this plan is adhered to, there will be most perplexing diversities in the sequence of assumptions and propositions in school teaching, not unmixed with inaccuracy of expression. The present writer knows from experience that it is necessary for an examiner to keep before him several books on geometry when dealing with the work of various schools, owing to the fact that a proposition which one pupil thinks it necessary to prove another assumes as an axiom. Moreover, the whole of the pupils of a school are sometimes found to speak of a circle as touching a triangle at its three vertices. This is a matter dependent on the individual teacher, and it cannot be cured by any syllabus.

There are, of course, several excellent text-books on geometry, with little difference in the order of propositions, but no one of them is universally adopted. The successful reformation of the teaching of geometry seems to require an authoritative text-book which will serve as a definite guide to all teacherssuch as that sanctioned by the Minister of Education in France. In the absence of such a definite guide, the present somewhat chaotic system will continue.

The writer of this article suggested, in the columns of Nature, in the early days of the reformed system, that such an authoritative book should be issued conjointly by the universities, but the university authorities felt difficulties. Why should not the Board of Education issue such a work? Its recent circular is in itself an excellent syllabus, but the practical teacher will regard it simply as one more added to the bundle which he already possesses.

There is one recommendation in the circular with which it is impossible to agree :- "Axioms and postulates should not be learnt or even mentioned "-tha: is to say, they are to be treated as suppressed premises. Now every mathematical physicist encounters occasionally what seems to be a fundamental contradiction of some proved result with other known results, and it is only after it is pointed out to him that his reasoning contains a suppressed premise that the difficulty is removed. The neglect of the explicit recognition of an axiom is the same in kind as the suppressing of an important premise.

Two excellent sentences, containing a fundamental truth, must be quoted from the circular :-- "It should be frankly recognised that unless the power of doing riders has been developed, the study of the subject is a failure. Although examining bodies may continue to pass candidates who merely reproduce proofs they have learnt, eked out by definitions or other matter, masters should not be satisfied with this; the only proof of knowledge worth having is the pozer of applying it to new matter." (The italics are ours.) This is, indeed, a great truth, the importance of which in the teaching of applied mathematics is still greater than it is in the teaching of geometry, and one which every teacher should lay to heart.

George M. Minchin.

\section{PHOTOMETRIC UNITS.}

$A \mathrm{~N}$ important announcement with regard to the photometric units maintained at the Bureau of Standards, America, the Laboratoire Central d'Électricité, Paris, and the National Physical Laboratory, Teddington, has been issued by the Bureau of Standards in its Circular, No. $\mathbf{1}_{5}$, dated April I, I909. It was at first intended to make this announcement simultaneously in America, France, and Great Britain, but circumstances prevented this. It is desirable, however, to state authoritatively that the agreement described in the subjoined memorandum has been arrived at, and has the approval of the gas referees; and that the photometric standards of the National Physical Laboratory are being maintained in accordance with it.

\section{R. T. Glazebrook.}

\section{Memorandum as to Photometric Units.}

In order to determine as accurately as possible the relations between the photometric units of America, France, Germany, and Great Britain, comparisons have been made at different times during the past few years between the unit of light maintained at the Bureau of Standards, Washington; at the Laboratoire Central d'Electricité, Paris; at the Physikalisch-Technische Reichsanstalt, Berlin; and at the National Physical Laboratory, London.

The unit of length at the Bureau of Standards has been maintained through the medium of a series of incandescent electric lamps, the values of which were originally intended to be in agreement with the British unit, being made 100/88 times the Hefner unit.

The unit of light at the Laboratoire Central is the bougie decimale, which is the twentieth part of the standard defined by the International Conference on Units of 1884 , 